$\mathrm{DE}$

M E D I C I N A

T R O P I C A L

$\mathrm{DE}$

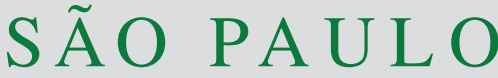

JOURNAL OF THE SÃO PAULO INSTITUTE OF TROPICAL MEDICINE

1Universidade Federal de Minas Gerais, Pós-Graduação em Ciências da Saúde: Infectologia e Medicina Tropical, Belo Horizonte, Minas Gerais, Brazil

${ }^{2}$ Hospital Eduardo de Menezes, Ambulatório de Dermatologia, Belo Horizonte, Minas Gerais. Brazil

${ }^{3}$ Secretaria de Estado de Saúde de Minas Gerais, Belo Horizonte, Minas Gerais, Brazil

${ }^{4}$ Faculdade de Saúde e Ecologia Humana (FASEH), Vespasiano, Minas Gerais, Brazil

Correspondence to: Edilamar Silva de Alecrim

Hospital Eduardo de Menezes, Ambulatório de Dermatologia, Rua Doutor Cristiano Rezende, 2213, CEP 30622-020, Bonsucesso, Belo Horizonte, MG, Brazil Tel: +553133285056

E-mail: edilamarenf@yahoo.com.br

Received: 30 August 2018

Accepted: 29 November 2018

\section{Reading of the Mitsuda test: comparison between diameter and total area by means of a computerized method}

\author{
Edilamar Silva de Alecrim ${ }^{1,2}$, Ana Thereza Chaves ${ }^{1}$, Luiz Alberto Bomjardim \\ Pôrto $^{2}$, Maria Aparecida de Faria Grossi ${ }^{3,4}$, Sandra Lyon ${ }^{2,4}$, Manoel Otávio da \\ Costa Rocha ${ }^{1}$
}

\section{ABSTRACT}

The Mitsuda test is a skin test based on the individual's immune response through late and highly specific hypersensitivity reaction to the Mycobacterium leprae bacillus. A negative reaction identifies individuals who present a higher risk of becoming ill if exposed to $M$. leprae and, if they become ill, to develop the virchowian form of disease. The Mitsuda test reading is performed by means of a millimeter ruler. The dermatoscopy is a method that has not been used in the evaluation of cutaneous tests, although its use has increased in several areas. The study aimed to compare the results between the standardized reading and the total area of the Mitsuda test obtained by a computerized method which was structured by the association of digital dermatoscopy, the Dermatology Web system and the Image Tool 3.0 software. Data collection was performed at the Dermatology Outpatient Clinic of the Eduardo de Menezes Hospital, in Belo Horizonte, from November 2015 to August 2016. The sample consisted of 100 leprosy domiciliary contacts. There was an excellent agreement between the Mitsuda test (diameter and area), with a coefficient greater than $80 \%$, and an excellent correlation with the Spearman's correlation coefficient (0.936). The intraclass correlation coefficient indicated a low (0.219) but significant agreement between the two measurements. In conclusion, there is a significant correlation between the standardized reading and the total area of the Mitsuda test. Digital dermoscopy can be an alternative instrument of evaluation, allowing the computerization and recording of the Mitsuda test.

KEYWORDS: Leprosy. Mitsuda test. Dermatoscopy.

\section{INTRODUCTION}

The Mitsuda test is a skin reaction based on a delayed individual hypersensivity response of cellular type and high-specificity against the Mycobacterium leprae bacillus. It shows the ability of macrophages to digest bacilli that have been phagocytosed. A positive reaction indicates that a person's macrophages are capable of destroying Hansen's bacilli. A negative reaction identifies individuals who, if exposed to M. leprae, present a higher risk of becoming ill and, if they become ill, of developing the virchowian form of disease. The test helps classifying patients with leprosy of the indeterminate and dimorphic groups. Macroscopic and histological responses to Mitsuda test are very similar between contacts and patients ${ }^{1}$.

The Mitsuda test reading was standardized at the Madrid International Congress in 1953. The reading technique is performed using a millimeter ruler, and the value is obtained from the mean of the largest diameters².

Aside from the Mitsuda test applicability in clinical practice for the classification 
of patients with leprosy, the test makes it possible to identify contacts that may develop virchowian leprosy and also to adopt preventive actions for contacts with negative reactions ${ }^{3}$. This justifies its use from a clinical and epidemiological point of view.

Considering that the Mitsuda test is not a well delimited circle in every case and can manifest as an irregular area, we sought to verify if there is a congruence between the traditional form of measurement and the measurement of the total area of reaction. The objective was to compare the results between the standardized reading and the total area of the Mitsuda test obtained by a computerized method. By using this procedure, one could correlate the two forms of measurement with the quality of the cellular immune response in new studies.

In order to allow the recording of the Mitsuda test reading and the calculation of the area, a computerized method was adopted structured associating the digital dermatoscopy, the Dermatology Web system and the Image Tool 3.0 software.

Dermoscopy is a noninvasive diagnostic method in vivo that assists in the evaluation of pigmented skin lesions. It is also referred to as surface microscopy, dermoscopy or epiluminescence microscopy. It allows the observation of structures of the epidermis, the dermoepidermal junctionand the papillary and superficial reticular dermis which are not observable by the naked eye $e^{4-6}$.

The device used to perform the examination is the dermatoscope, a portable instrument that allows the standard increase of an image. The digital dermatoscope is a portable device that allows an image to be recorded through a digital camera. The image can be increased approximately 70 -fold maintaining its definition and allowing it to be captured and stored ${ }^{5-8}$.

The primary indication for the dermatoscopy is to establish the early diagnosis of melanoma and assist in the differential diagnosis of melanocytic skin lesions. In recent years, the use of dermatoscopy has been increasing in various areas ${ }^{5,7,8}$ and it may also be more useful in the context of leprosy.

The Dermatology Web system is used for the photographic documentation of dermatological treatments and encompasses photo storage functionality. It consists of a digital image system that can be used on any mobile platform or computer connected to the Internet. It has the login password feature and information technology tools that ensure the security and confidentiality of data stored in medical records 9 .

The area calculation was performed using the Image Tool 3.0 software. This software was developed at the University of Texas for Microsoft Windows. It has several tools that allow the user to view, edit, analyze, process, save and print grayscale or color images ${ }^{10}$.

In view of the above, this study intends to contribute to innovation and optimization of the Mitsuda's test use, besides contributing to the development of new related studies.

\section{MATERIAL AND METHODS}

This research was carried out according to the Resolution 466/12 of the Brazilian National Health Council - Guidelines and norms regulating research involving human beings. The project was approved by the Ethics and Research Committee of UFMG, according to CAAE $\mathrm{N}^{\circ} 2554988016000005149$ and by the Ethics Committee of Eduardo de Menezes Hospital.

Data collection was performed at the Dermatology Outpatient Clinic of Eduardo de Menezes Hospital, in Belo Horizonte, from November 2015 to August 2016. The sample consisted of leprosy household contacts.

The Mitsuda antigen bottles were kindly provided by the Immunology Technical Team of Lauro de Souza Lima Institute, Bauru, Sao Paulo. Mitsudine is a suspension of intact bacilli obtained from hansenomas of previously non-treated patients and heat-killed. The concentration was $6.0 \times 10^{7}(60$ million bacilli / $\mathrm{mL})$ or $6.0 \times 10^{6}$ bacilli in the inoculum corresponding to $100 \mathrm{uL}(0.1 \mathrm{~mL})$.

After signing the consent form, $0.1 \mathrm{~mL}$ of the Mitsuda antigen was administered in the middle third of the anterior face of the right forearm of the contacts. They were instructed to return after 21-28 days to read the test. The Mitsuda reaction was read according to the following protocol.

\section{Standard reading}

To identify the induration area after observation of the appearance of the reaction, palpation of the test application site, delimitation of the outer edges and positioning of the millimeter ruler to measure transverse and horizontal diameters were conducted. If erythema was observed beyond the limits of induration, it was not considered in the measurement. Diameters were then recorded in medical records and in the research records. The test was considered positive if the mean diameter was greater than or equal to five millimeters, and negative if the value was less than five millimeters.

\section{Reading with computerized method}

A Dino-LiteAM4113ZT dermatoscope featuring 1.3 Mega Pixel resolution and USB 2.0 interface (Figure 1) was used. The digital dermatoscope was brought close to 
the skin of the contact and a record of the Mitsuda test reaction was made by means of the software Dermatologia web (Figure 2).

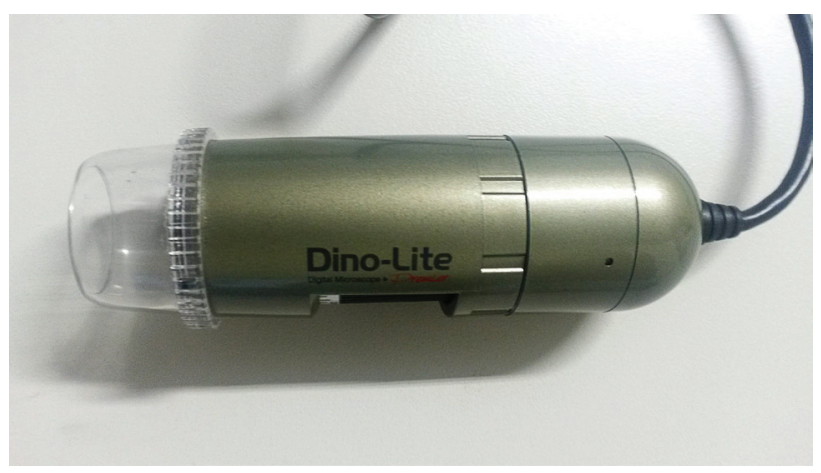

Figure 1- Dino-LiteAM4113ZT dermatoscope which features 1.3 Mega Pixel resolution and USB 2.0 interface.

The web dermatology platform can be accessed at www.dermatologiaweb.com.br ${ }^{9}$ upon accessing the platform and logging in. Then, the reaction was recorded according to the sequence described below:

a) register data of the individual;

b) select the dermoscopy option;

c) record the characteristics of the reaction;

d) select the body area where the reaction is present;

e) capture the image by dermatoscope;

f) save the data.

After the digital recording of the reaction, the area calculation was performed using the Image Tool 3.0 software. This software has the ability to calibrate the image in millimeters, provided that the image has been recorded with a millimeter ruler close to the reaction.
After performing the delineation of the contours of the reaction, the program presents the result of the total area in square millimeters ${ }^{10}$. The technique for area calculation is described below:

a) open the program, click file, open image;

b) the selected image will be displayed;

c) select the settings, select the calibrate spacial measurements;

d) identify in the ruler the correspondence to one millimeter, enter the value to be calibrated: one millimeter;

e) select "analysis" select the area;

f) select the area to be calculated;

g) after the selection, the program will calculate the delimited area;

h) record the area and save the calculation: file/save as (Figure 3).

\section{Evaluation of results}

In order to evaluate the agreement between the area of the Mitsuda test obtained from dermatoscopy and the area obtained from mathematical calculations, the Intraclass Correlation Coefficient was used because it is a numerical variable. Estimations of the coefficients with respective Confidence Intervals of $95 \%$ (95\% CI) were performed.

\section{RESULTS}

An excellent agreement was observed, with a coefficient over $80 \%$ and an excellent correlation between the Mitsuda test (diameter and area), according to the Spearman's correlation coefficient $(0.936)$. This result indicates that an increase in Mitsuda test area is associated with an increase

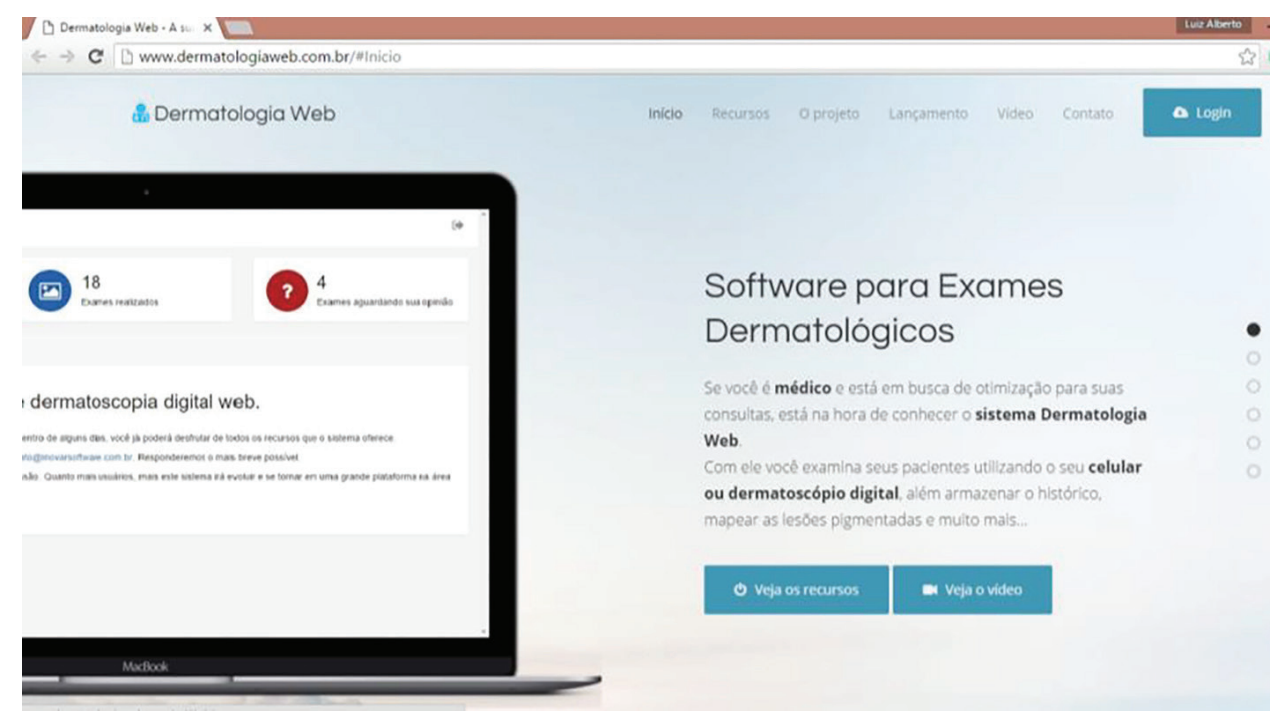

Figure 2 - Software dermatologia web: this system is used for photographic documentation of dermatological treatments and encompasses photo storage functionality. 


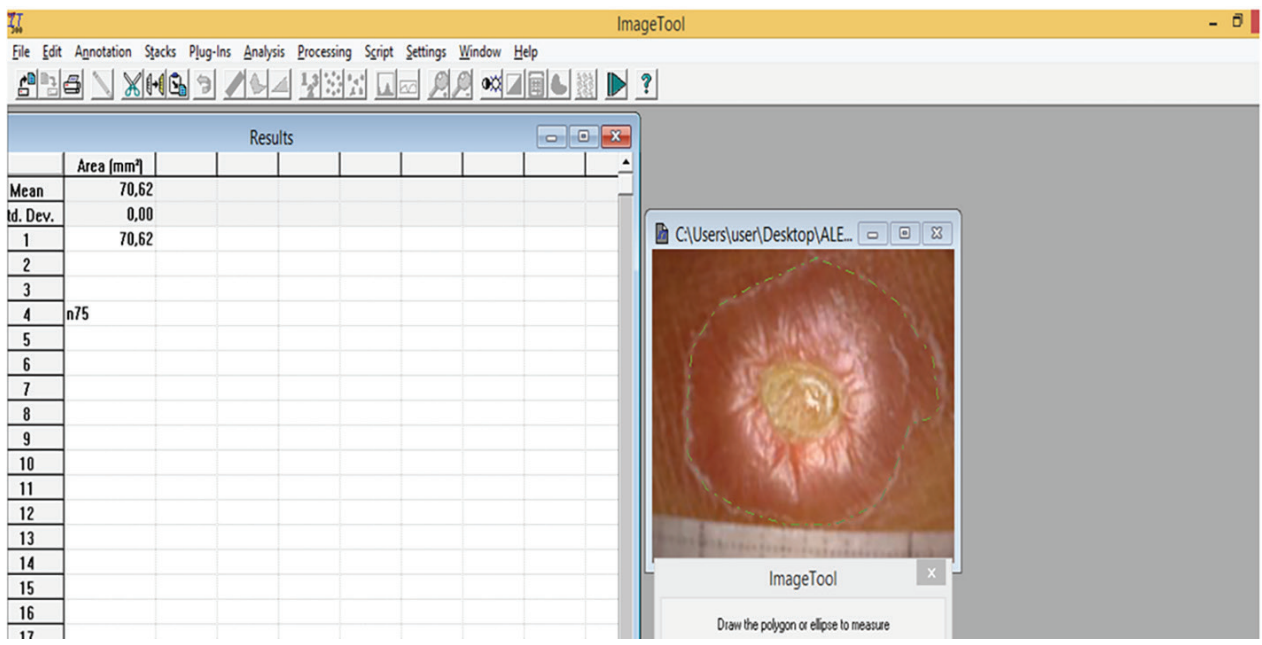

Figure 3 - The calculation of the Mitsuda test area using the Image Tool 3.0 software.

Table 1 - Correlation and concordance between measurements of the Mitsuda test area and the standardized reading in leprosy contacts, HEM Ambulatory, 2015-2016.

\begin{tabular}{lcc}
\hline Mitsuda test area $\left(\mathrm{mm}^{2}\right) \times$ Mitsuda $(\mathrm{mm})$ & Coefficient & P-value \\
\hline Spearman Correlation & 0.936 & $<0.001$ \\
Intra-Class Correlation (Concordance) & 0.219 & 0.014 \\
\hline
\end{tabular}

in the diameter of the Mitsuda test (Table 1). The intraclass correlation coefficient indicated a significant, although low (0.219) agreement between the two measurements. Areas between $18.56 \mathrm{~mm}^{2}$ to $19.55 \mathrm{~mm}^{2}$ corresponded to the result of $5 \mathrm{~mm}$ in the conventional reading.

A significant correlation was observed between the two readings of the Mitsuda's test (diameter and area), according to the Spearman's correlation coefficient (0.936).

\section{DISCUSSION}

The computerized technique to obtain the Mitsuda test area can be used as an alternative to the reading of the Mitsuda test, since it presents an excellent correlation with the standardized reading. The low agreement observed can be related to the variability of the results in the calculation of the total area, which varied between 0 and 79 square millimeters $\left(\mathrm{mm}^{2}\right)$, while the measurement by the diameter generally vary from 0 to 10 millimeters.

The use of computerized tools offers possibilities for collecting and storing information, facilitates scientific researchand contributes to clinical practice ${ }^{11,12}$. This method provides computerization of the record, to the watchfulness of leprosy contacts and to the structuring of new research related to Mitsuda's test. This method of analysis enables the registration, computerization and greater precision of results. The advantage of using the area calculation with the computerized method is that it can be a useful tool to improve reading precision and it allows the computerization of records. By means of computerized methodology one can obtain both, the diameters mean and the total area of the Mitsuda test.

Regarding the watchfulness of leprosy contacts, the Mitsuda test could be a cost-effective method to evaluate the cellular immunity, when compared to other immunological tests.

The application of this method has potential for the immune response evaluation in leprosy patients and contacts. The registration of the Mitsuda test is important for the monitoring of leprosy contacts, mainly of the ones with greater risk of illness. The image registration can be used for mapping in order to identify in the contact population, and hose who would probably have lower cellular immunity responses in relation to leprosy. This would be a direct contribution to the epidemiological watchfulness of contacts.

According to the results of the present study, this method can be used in reference centers of leprosy. However, it can be extended to other health services. In Brazil, the implementation of Tele Saúde in the Computerization System of the National Immunization Policy is an example that it is possible to work with technological tools in the cities $^{13,14}$.

The proposed technique has an innovative aspect not only to evaluate the Mitsuda test, but also in the scientific field. From the computerized reading, new perspectives on 
the interpretation of the test can be evaluated and discussed as well as the evaluation of the total area in immunological or genetic studies.

Since leprosy is a neglected disease ${ }^{15}$, additional efforts of the scientific community and health services need to be made so that new methods and technologies can be inserted in its prevention and control.

\section{ACKNOWLEDGMENTS}

We are thankful for Vânia Nieto Brito de Souza, from Lauro de Souza Lima Institute, Bauru, São Paulo, Brazil, for providing the Mitsuda antigen. This work was supported by Conselho Nacional de Desenvolvimento Científico e Tecnológico (CNPq No 474796/2012-4), Fundação de Amparo à Pesquisa do Estado de Minas Gerais (FAPEMIG$\mathrm{N}^{\circ}$ PMM-00501-13) and Universidade Federal de Minas Gerais (UFMG).

\section{REFERENCES}

1. Bechelli LM, Souza PR, Quagliato R. Correlação entre os resultados da leitura clínica e do exame histopatológico da reação de Mitsuda. Rev Bras Leprol. 1959;27:172-82.

2. Wade HW, Prieto JG, Vegas M, Basombrio G, Cochrane RG, Khanolhar VR, et al. Classification. Int J Lepr. 21:504-16.

3. Convit J, Avila JL, Goihman M, Pinardi ME. A test for the determination of competency in clearing bacilli in leprosy patients. Bull World Health Organ. 1972;46:821-6.

4. Argenziano G, Soyer HP, Chimenti S, Talamini R, Corona R, Sera F, et al. Dermoscopy of pigmented skin lesions: results of a consensus meeting via the internet. J Am Acad Dermatol. 2003;48:679-93

5. Azulay RD, Azulay DR. Dermatologia. $3^{\mathrm{a}}$ ed. Rio de Janeiro: Guanabara Koogan; 2004.

6. Campos-do-Carmo G, Ramos-e-Silva M. Dermoscopy: basic concepts. Int J Dermatol. 2008;47:712-9.
7. Morales-Callaghan AM, Castrodeza-Sanz J, Martínez-García G, Peral-Martínez I, Miranda-Romero A. Estudio de correlación clínica, dermatoscópica e histopatológica de nevus melanocíticos atípicos. Actas Dermosifiliogr. 2008;99:380-9.

8. Sampaio SA, Rivitti EA. Dermatologia. $3^{\mathrm{a}}$ ed. rev. ampl. São Paulo: Artes Médicas; 2008.

9. Porto LA. DermatologiaWeb: um software para os dermatologistas. [cited 2018 Jun11]. Available from: http://drluizporto.com.br/ dermascopiaweb-um-softwares-para-os-dermatologistas/

10. Sousa AT, Vasconcelos JM, Soares MJ. Software Image Tool 3.0 as an instrument for measuring wounds. J Nurs UFPE On Line. 2012;6:2569-73.

11. Wechsler R, Anção MS, Campos CJ, Sigulem D. Computer science in the doctor's office. J Pediatr (Rio J). 2003;79 Suppl $1: \mathrm{S} 3-12$.

12. Wyatt JC, Liu JL. Basic concepts in medical informatics. J Epidemiol Community Health. 2002;56:808-12.

13. Maldonado JM, Marques AB, Cruz A. Telemedicine: challenges to dissemination in Brazil. Cad Saude Publica. 2016;32 Suppl 2:e00155615.

14. Brasil. Ministério da Saúde. Gabinete do Ministro. Portaria ${ }^{\circ}$ 2.363, de 18 de outubro de 2012. Institui repasse financeiro do Fundo Nacional de Saúde aos Fundos de Saúde dos Estados, Distrito Federal e Municípios, por meio do Piso Variável de Vigilância e Promoção da Saúde, para fomento na implantação do Sistema de Informação do Programa Nacional de Imunizações (SI-PNI) e Sistema de Informação de Agravos de Notificação (SINAN), no âmbito das unidades de saúde. [cited 2018 Nov 28]. Available from: http://bvsms.saude.gov. br/bvs/saudelegis/gm/2012/prt2363_18_10_2012.html

15. World Health Organization. Integrating neglected tropical diseases into global health and development: fourth WHO report on neglected tropical diseases. Geneva: WHO; 2017. [cited 2018 Oct 20]. Available from: http://apps.who.int/iris/bitstre am/10665/255011/1/9789241565448-eng.pdf?ua=1 